\title{
ARTIGOS
}

\section{A AMIZADE COMO PAISAGEM CONCEITUAL E O AMIGO COMO PERSONAGEM CONCEITUAL, SEGUNDO DELEUZE E GUATTARI}

\author{
Hélio Rebello Cardoso Jr.* \\ herebell@uel.br
}

RESUMO $O$ presente artigo parte da proposição de uma "pedagogia do conceito" segundo Deleuze e Guattari. Com base na mesma, isola-se e explora-se a idéia de que todo pensamento exige, como sua condição interna, "traços relacionais". Dos traços relacionais definidos pela pedagogia do conceito, enfatiza-se o "amigo" como personagem que caracteriza um dado pensamento. Procura-se, em seguida, definir, panoramicamente, o que seriam o amigo e a paisagem da amizade em filosofias como a de Platão, Nietzsche, Heidegger e Foucault.

Palavras-Chave Deleuze; Guattari; Filosofia; Conceito; Amizade

ABSTRACT This paper begins with the proposal of a "pedagogy of concept" according to Deleuze and Guattari. On this basis, I emphasize and explore the assertion that every thought demands relational traces" as their internal condition". Among the relational traces defined by this pedagogy of concept, I selected "friend" as a character who distinguishes a given thought. I try, after that, to define, generally what friend and the scene of friendship in Plato's, Nietzsche's, Heidegger's and Foucault's philosophies are.

Keywords Deleuze; Guattari; Philosophy; Concept; Friendship

* Doutor em Filosofia. Professor da Universidade Estadual Paulista (Unesp). Artigo recebido em junho de 2005 e aprovado em julho de 2006. 
É sintomático o protesto que fazem Deleuze e Guattari quando assinalam que o amigo e amizade são preocupações quase ausentes do pensamento filosófico, sendo uma das raras exceções a esta regra o livro $A$ amizade de Maurice Blanchot. ${ }^{1}$ Não que os filósofos não se tenham preocupado com a questão, mas amigo e amizade aparecem tratados, quase exclusivamente, do ponto de vista ético. Parece estranho, a Deleuze e a Guattari, que essa temática tenha sido tão escassamente abordada do ponto de vista da própria filosofia, já que, etimologicamente, como se sabe, o filósofo é o amigo do saber.

O "amigo" é um personagem que testemunha a origem grega da filosofia. O filósofo é o "amigo" da "sabedoria". Mas os amigos da filosofia seriam por isso, na justa medida em que prezam a sabedoria, amigos entre si? Estariam eles obrigados a uma reciprocidade compulsória devido ao objeto de sua amizade? E de que modos os amigos podem participar dessa amizade?

A amizade como marca da filosofia significa que tal relação surge a partir do próprio pensamento. $\mathrm{O}$ amigo é produzido por uma relação que se dá a partir do plano dos conceitos. Trata-se de um plano impessoal. O plano dessa amizade - que denominaremos doravante de amizade do conceito - é impessoal e, ao mesmo tempo, altamente diferenciável. Segundo Deleuze e Guattari, todo conceito emite certos "afectos" e "perceptos" que provocam sensações determinadas. Para se falar de modo simples, pode-se sentir um conceito como simpático ou antipático. ${ }^{2}$ Por exemplo, sabemos que Foucault tinha aversão ao conceito deleuzeano de "desejo", que ele considerava um dos traços do modo histórico de subjetivação característico do cristianismo (a "carne"); ${ }^{3}$ ao passo que Deleuze detestava o conceito foucaultiano de "prazer", que lhe parecia dizer respeito a trajetos limitados, por estar ligado a este ou aquele objeto de satisfação, e não a uma verdadeira força propulsora da vida. ${ }^{4}$

Esses afectos e perceptos emitidos pelos conceitos não são sentimentos que se confundam com os sentimentos vividos, num meio histórico, pelos tipos psicossociais dos filósofos que criaram aqueles conceitos. ${ }^{5} \mathrm{Na}$ verdade, ainda segundo Deleuze e Guattari, os dados sensíveis produzidos por um conceito não coincidem com os sentimentos do filósofo como pessoa ou, se coincidem, é como se outra pessoa os experimentasse, por isso, afirmam eles, "o rosto e o corpo dos filósofos abrigam esses personagens que lhes dão um

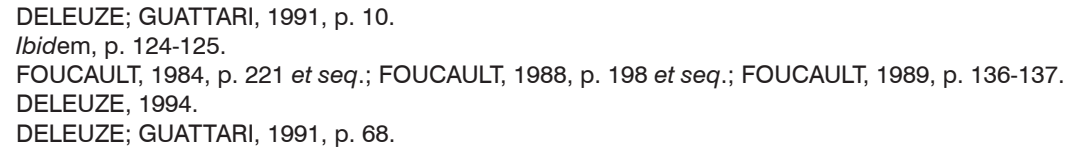


ar estranho, sobretudo no olhar, como se outra pessoa visse através de seus olhos" (Deleuze; Guattari, 1991, p. 71).

Os conceitos nos dão esses olhos que, dentro de cada um, são os olhos de outra pessoa. O olhar do conceito é uma sensação que não vem dos olhos dos sentidos ou dos sentimentos pessoais. Os conceitos nos fazem trocar olhares que não são de ninguém.

Mas como se pode ser amigo não sendo ninguém?

Tal indagação visa a explorar o território da amizade do conceito, pois se, como afirmávamos, trata-se de uma dimensão ou plano altamente diferenciável, então, pode-se detectá-la em certos períodos históricos ou mesmo em cada pensador tomado individualmente. Procuraremos, em seguida, definir e ilustrar, a partir dos elementos que acabamos de emprestar a Deleuze e Guattari, de modo apropriado à extensão do presente artigo, quatro tipos de amizade do conceito, a grega, a nietzscheana, a heideggeriana e a foucaultiana, destacando em cada uma os perceptos e afectos que compõem a amizade como paisagem e o amigo como personagem conceptual. Tal prospecção faz parte do que Deleuze e Guattari denominam "pedagogia do conceito". ${ }^{6}$

Ora, o que poderia ser uma amizade do conceito na Grécia Clássica, durante o século de ouro da filosofia, já que sabemos que foram os gregos que se inventaram enquanto amigos da sabedoria?

Nos textos platônicos, excluídos os sempiternos Sofistas, professores da ilusão retórica, os verdadeiros amigos da sabedoria são aqueles que estabelecem entre si um diálogo visando à posse potencial do conceito ou ao aprendizado de um dado conteúdo. Por isso, por exemplo, os filósofospersonagens de Platão não seriam, em primeiro lugar, amigos que, por uma decisão pactuada, se reuniriam para passar longas horas discutindo sobre a Idéia ou essência das coisas. Ao contrário, a amizade é uma condição para que o pensamento se exerça. Mas isso não quer dizer que a amizade seja um pressuposto do pensamento, pois ela começa junto com o pensamento. A amizade, falando com mais propriedade, é uma condição interna ao pensar, no sentido definido por Deleuze e Guattari, como "presença intrínseca ao pensamento". ${ }^{7}$ Somente enquanto os amigos da sabedoria estão em posição de diálogo, isto é, estabelecem entre si certa disputa quanto à verdade de um tema ou conceito, pode-se dizer que há filosofia e aprendizado. Não pode haver pensamento sem o amigo. 
Entre os amigos da filosofia, estabelece-se uma certa dialética que Platão denomina de amphibetesis. É uma dialética da amizade que permite, inclusive, definir as diferenças entre os principais ofícios e profissões da cidade, culminando com a própria caracterização do governante legítimo, que é um tipo especial de "amigo da sabedoria". ${ }^{8}$ Cada filósofo coloca-se como amigo da coisa, seja, por exemplo, a verdade, o amor, o humano, a cidade, cujo conceito pretende alcançar. Sendo assim, com relação à coisa disputada, dois indivíduos confrontam-se como pretendentes que rivalizam a coisa em questão. É somente na condição de amizade com relação à coisa disputada que a essência ou verdade dessa coisa poderia ser almejada.

A amizade filosófica grega fundava-se na idéia de que o mundo causa admiração - thaumazein, uma espécie de curiosidade que desembaraça o homem do mundo das aparências e o faz indagar pelo ser das coisas, a partir de uma postura propiciada pela razão. Essa atitude de admiração diante do mundo, embora não leve todos os homens incontinente à mesma verdade, pelo menos, os coloca numa situação de disputa quanto ao objeto. Nessa medida, como observamos, todo homem e todo filósofo é um amigo. E a sabedoria só pode ser ensinada na base dessa amizade que rivaliza.

Na modernidade, principalmente a partir de Nietzsche e Heidegger, a admiração filosófica do mundo é tomada em um outro sentido.

A admiração filosófica, com Nietzsche, tinge-se de uma certa desconfiança quanto à probidade da criação filosófica e, portanto, procede-se a uma reavaliação da amizade filosófica. Com Heidegger, de uma determinada maneira, o caráter da admiração filosófica do mundo e, por conseguinte, a relação de amizade entre os filósofos fica envolvida por uma atitude de terror ou de estranhamento diante de um acontecimento que ultrapassa e congela os poderes da razão e, por isso mesmo, deixa o homem em uma espécie de indeterminação ou suspensão que lhe retira o poder de indagar sobre a essência do mundo dos entes.

O grande problema da filosofia contemporânea é, portanto, como seguir pensando e ensinando após este evento radical que esgota os poderes racionais. De certo modo, os amigos não podem mais se entregar com toda a confiança à própria relação de amizade que os unia. Já não podemos ser amigos como o eram os gregos, pois, se é verdade que o mundo causa admiração, agora, tratase de uma admiração que extrapola nossa consciência, colocando em cheque a dialética comedida dos amigos da sabedoria. 
Vejamos, à guisa de ilustração, como fica a amizade nessa terra devastada que é a filosofia após Nietzsche e Heidegger.

Foi Nietzsche, na análise que faz da metafísica platônica, quem alertou para o fato de que amigos gregos nos legaram uma imagem perigosa da filosofia. Nietzsche teria mostrado que o jogo entre os amigos da filosofia possuía um vício de concepção, qual seja, a vontade de verdade. Haveria, por trás da filosofia grega, um certo adestramento moral baseado na doutrina de que as idéias verdadeiras possuiriam uma essência estável e que, por isso, sua origem seria irretocável. Sendo assim, Nietzsche teria mostrado que a dialética entre os amigos da filosofia estava fundada em um falso ídolo. A disputa da verdade não seria o melhor caminho para que dois pretendentes conquistem a essência de uma coisa.

Segundo Nietzsche, o filósofo precisa praticar uma certa "arte da desconfiança", ${ }^{9}$ sendo seu principal instrumento o "martelo". ${ }^{10}$ Estamos distantes demais do diálogo filosófico grego, pois com Nietzsche os filósofos aprendem que as idéias não são extraídas de um céu filosófico que seria alcançado por meio de uma espécie de contemplação. Nietzsche demonstra que os conceitos têm uma origem sublunar, que são criações, e sofrem por isso as vicissitudes empíricas das experimentações. Os conceitos não estão prontos, à espera de que os filósofos mais argutos, mais votados à sua contemplação, mais amigos da sabedoria, venham resgatá-los de seu recesso supra-sensível. Os conceitos têm uma origem, em sua maior parte, baixa.

$\mathrm{E}$ os conceitos que, tendo sido criados, são promovidos a entidades do mundo das idéias através do artifício ou da ficção da transcendência, são duplamente enganosos. Uma vez, porque camuflam sua origem mundana; outra vez, porque propagam o engodo de que a transcendência pode ser criadora, de certo modo, substituindo e aureolando o filósofo. A lição de Nietzsche é clara: temos de desconfiar dos conceitos por causa de seus criadores.

A partir dessa clivagem surgem dois campos da filosofia, cada um com um tipo de amigo da sabedoria que lhe é próprio. Em um primeiro campo, segundo Nietzsche, estão os "operários filósofos" 11 inspirados no "nobre modelo de Kant e Hegel". ${ }^{12}$ Os operários da filosofia atribuem-se a difícil tarefa de avaliar os conceitos legados pela tradição, zelando pelos valores estabelecidos. Em um outro campo, estão os "verdadeiros filósofos"13 para os quais "conhecer

9 NIETZSCHE, 1970, p. 215-216.

10 NIETZSCHE, 1954, p. 676 (§ 211).

11 NIETZSCHE, 1954, p. 676 (§ 211).

12 ldem.

13 Idem. 
equivale a um criar". ${ }^{14}$ Estes últimos utilizam os produtos dos operários da filosofia como um martelo para quebrar os conceitos do passado, a fim de que novos valores sejam criados. Nietzsche rejeita cabalmente a alcunha de "amigo da sabedoria” para os filósofos, que, pelo contrário, precisam ser inimigos de seu tempo. Afirma ele:

até agora, todos esses favorecedores do homem que se chamam filósofos - os quais por si mesmos raramente tiveram o sentimento de serem os amigos da sabedoria, pois são antes loucos e pontos de interrogação perigosos - acharam seu trabalho duro, indesejado, ingrato e impreterível, mas do qual reconheceram a grandeza ao representar a má consciência do tempo em que viveram. (Nietzsche, 1954, p. 677, grifos nossos)

Por isso, não só na relação do filósofo com seu tempo, mas igualmente entre o campo dos operários filósofos e o do filósofo criador, estabelece-se uma relação de força que envolve proximidade e desconfiança, simultaneamente. Por um lado, se os operários filósofos predominam, os conceitos do passado, com os valores que carregam, são, de certo modo, eternizados. Nesse caso, constitui-se uma amizade perniciosa entre os filósofos, uma amizade baseada na moral do escravo, como diria Nietzsche, pela qual os valores transcendentes ou superiores mantêm os valores estabelecidos pelo passado e cerceiam a criação filosófica com vista aos valores do futuro. Por outro lado, se esses operários filósofos se deixam instrumentalizar e são tomados como martelos pelos filósofos criadores, então a amizade entre filósofos recebe uma marca positiva.

Ora, o que dizer da amizade entre filósofos, de um modo geral?

Parece-nos que a essa amizade está reservado um distanciamento necessário, devido ao envolvimento de cada filósofo com a sua própria tarefa de demolição dos conceitos e valores do passado. O filósofo torna-se uma espécie de Hércules - operário e criador -, para quem a tarefa encerra determinada concentração olímpica que o afasta do convívio e do diálogo. $\mathrm{O}$ filósofo olímpico se cala e a amizade entre filósofos passa a ser uma espécie de encontro virtual, não realizado, porém prenhe de promessas, na qual cada amigo só se aproxima por vislumbre, no recesso de um esforço, como um aceno ou no paralelismo dos trajetos que conduzem a caminhos necessariamente desencontrados. A amizade dos filósofos, contraditoriamente, é efeito do maior alheamento possível, pois, afirma Nietzsche, "será o maior aquele que souber ser o mais solitário" (Nietzsche, 1954, p. 678) e "quem é solitário 
por um capricho da natureza, em razão de uma estranha mescla de desejos, talentos e aspirações, sabe que maravilha inconcebivelmente elevada é um amigo" (Nietzsche, [s.d.], p. 97). Pois afirma Nietzsche em outro momento:

Conheço o espírito de muitos homens /Mas não sei quem sou eu mesmo! /Meu olhar é demasiado próximo de mim /Não sou o que vejo e o que vi. /Eu seria de maior proveito para mim /Se de mim pudesse estar mais longe. /Não tão distante quanto meu inimigo, claro! /Já o amigo mais próximo está longe demais /Mas entre nós dois há o meio caminho! (Nietzsche, 2002, p. 28-29, grifos nossos)

E o diálogo, no sentido platônico, passa a ser intimamente execrado pelo filósofo, pois que lhe parece um exercício afetado, eivado de uma dialética viciosa, na qual não se pode reconhecer uma amizade criadora, como assevera Nietzsche, o diálogo filosófico é uma "espécie de dialética assustadoramente autocomplacente e infantil" (Nietzsche, 1954, p. 1028). Um mestre-filósofo sempre reivindica, enquanto amigo do discípulo, um certo silêncio, a fim de esquivar-se do estatuto falacioso do diálogo, ou seu diálogo se volta para discípulos não humanos, como na relação entre Zaratustra e seus animais. A própria linguagem, para Nietzsche, tem uma função reativa, as palavras sempre chegam depois da hora, quando o corpo já processou o acontecimento.

Em que outro ambiente descorçoado se encontra o amigo-filósofo no pensamento de Heidegger?

Heidegger situa os grandes sistemas filosóficos como poderosas maquinarias que produzem o esquecimento do ser e fazem os homens voltarem-se para o mundo dos entes, isto é, das coisas existentes, distanciando-se do ser que guarda a verdade de sua essência. Em um mundo que vive no esquecimento, o encontro com o ser se torna a tarefa filosófica mais importante e também a mais difícil. Segundo a famosa imagem pastoral e silvestre que nos legou Heidegger, os homens moram na clareira de uma floresta que os envolve, ao mesmo tempo expostos à luminosidade ofuscante dessa clareira ou abertura, na qual o ser lhes concede presença, e dela parcialmente protegidos dentro de uma morada chamada linguagem. Se o ser não comparece à ou se retira $d a$ clareira onde os habitantes da floresta se agrupam, então o Esquecimento lança sobre o homem sua sombra. A linguagem, devido ao seu lugar na clareira, sofre as vicissitudes do esquecimento do ser, pois, enquanto morada do ser em que o homem se aninha, a linguagem é como uma membrana que protege do brilho ofuscante do ser na clareira e, ao mesmo tempo, absorve e traduz a verdade fustigante desse brilho.

Então, como é possível a filosofia em um mundo marcado pelo esquecimento do ser? E o que dizer da amizade pela sabedoria em um mundo pelo avesso? Diz Heidegger, 
o esquecimento do ser foi, muitas vezes, representado como se fosse, para expressá-lo numa imagem, o guarda-chuva que a distração de um professor de filosofia esqueceu em algum canto. Entretanto, o esquecimento não afeta a essência do ser como algo aparentemente dela separado. Ele pertence à tarefa do próprio ser, impera como destino de sua essência. (Heidegger, 1969, p. 50-51)

Mas o esquecimento do ser faz valer sua presença de duas maneiras, a saber, ou o homem vive sua indeterminação essencial como ente e encara o ser para questioná-lo ou, ao tentar determinar-se como ente dotado de uma essência especial entre os entes, procurando suplantar sua indeterminação essencial, será engolido pelo esquecimento do ser e seu fim anuncia uma catástrofe de ordem ontológica.

Enquanto a questão do ser não é posta na perspectiva do esquecimento, que a afeta essencialmente, o homem permanece na sombra do ser que se retira e sob a qual ele é esquecido, na medida em que equivocadamente questiona o ente. O homem, embora em pé de igualdade com todos os entes quanto a seu raio de ação, insinua-se por esta indeterminação: "o homem que investiga a questão" (Heidegger, 1978, p. 35). O homem é o "pastor do ser" por vocação, o humano confunde-se com o lugar por excelência a partir do qual se põe a verdade do ser, que ele é solicitado por isso a "velar e proteger" (Heidegger, 1979, p. 149-156). Ele "ganha a essencial pobreza do pastor, cuja dignidade reside no fato de ter sido chamado pelo próprio ser para guardar a sua verdade" (Heidegger, 1979, p. 163). O homem é um ente como um animal, um mineral ou uma máquina, mas ele não pode procurar sua essência entre os entes, com essa atitude ele somente encontraria o regozijo e usufruto de sua supremacia entre os entes, mas não exerceria a faculdade que essa superioridade de fato lhe confere, que é indagar a indeterminação de sua essência diante do ser.

O pastor do ser, por concessão e privilégio, está arremessado na "clareira do ser"; está na abertura, que é como uma dobra que envolve o ser e o homem num mesmo tecido ontológico, embora os diferenciando. O ser comparece na clareira constituindo a essência da verdade que se revela na vizinhança do homem; mas como, ao mesmo tempo, o ser do seu lado da dobra está velado para o homem, este mergulha numa não-verdade essencial que o põe numa distância intransponível com relação ao ser, já que essa não-verdade é a verdade do ser que permanece inexplorada como pura possibilidade.

O ser humano não está mais implantado no interior do círculo agonístico do ser, mas na abertura do ser para um horizonte indeterminado de eventos, com isso ressaltando seu arracionalismo e confrontando-o ao monstruoso e ao inumano como qualidades existenciais inerentes ao ser do homem. Os amigos da filosofia não estão mais envolvidos pelo círculo do diálogo em meio ao 
qual eles se reuniam para disputar a verdade. Os amigos estão congelados ou extáticos diante do que parece ser uma catástrofe ontológica, da qual eles não podem escapar nem se redimir. A própria linguagem, morada do ser, foi enodoada por esse evento indeterminado, de maneira que, como os homens somente podem pensar sobre as marcas do inumano e do irracionalismo que os abisma, o diálogo racional está impedido, deformado ou interrompido por inconsistências do silêncio.

O homem, segundo Heidegger, é chamado para a clareira ou dobra pelo próprio ser e aí se aninha numa morada chamada linguagem para ouvir silenciosamente a palavra do ser. Como pastor do ser, o filósofo vive como na imensidão das pastagens, nas planícies ou nas montanhas, em isolamento quase total com relação a outros pastores. Curiosamente, o que faz dos filósofos amigos é essa distância instransponível da solidão, que, ao mesmo tempo, é a condição da audição do ser. O amigo da sabedoria, segundo Heidegger, é mais humilde do que o eloqüente filósofo grego ou humanista. Heidegger diz, de um modo um tanto codificado, que precisamos ouvir o ser a fim de redefinir a existência do homem, pois o filósofo clássico é aquele que justamente perdeu a audição do ser, não sabe mais o lugar de pastor que o ser lhe reservou na clareira. $\mathrm{O}$ isolamento das imensidões e os ouvidos atentos aos ventos das paragens infindáveis é o que define a amizade do conceito em Heidegger. $\mathrm{O}$ mestre e o discípulo caminham silenciosamente por estas ermas paragens; o mestre apenas tem a ensinar a atitude da audição.

O que diria Foucault, enfim, sobre a amizade do filósofo?

Foucault teria declarado, segundo Deleuze, que "Heidegger sempre o fascinou, mas que somente podia compreendê-lo por meio de Nietzsche, com Nietzsche (e não o inverso)"(Deleuze, 1986, p. 120-121). Ou, ainda, "Foucault", declara Deleuze, "é seguramente, ao lado de Heidegger, mas de uma maneira totalmente diversa, aquele que mais profundamente renovou a imagem do pensamento"(Deleuze, 1990, p. 130-131).

A renovação operada por Foucault envolve principalmente o estatuto da clareira ou horizonte de indeterminação do mundo onde o ser se faz presente. Tal clareira, para Foucault, não é mais a imensidão onde o pastor se põe à escuta, ou melhor, onde a luz dessa abertura com o ser torna-se audível. Não se trata de uma relação solitária de abertura, a clareira para Foucault é, antes, um campo de forças. O pastor do ser, o amigo-pastor, não está numa situação de escuta para colocar em palavras a visão diante da abertura. Para Foucault, esclarece uma vez mais Deleuze, a clareira do ser está revolvida pelo modo forçado pelo qual o que se vê e o que se diz convivem, devido aos modos 
históricos de se ver e de se enunciar. ${ }^{15}$ É o mais essencial, na maneira como Foucault percorre o plano heideggeriano de amizade: o ver e o dizer não são (e nem podem ser) congruentes, entre eles há a espessura histórica da episteme e a deflagração das relações de poder que são, com relação aos enunciados e às visibilidades, constitutivas. O amigo foucaultiano vê a clareira do ser com os olhos nietzscheanos, por isso, relativamente, a aprazível posição do pastor que apascenta é substituída pela do guerreiro que se desloca em um campo de batalha. Os amigos são amigos de luta, pois, segundo afirma Veyne,

Foucault era um guerreiro, me dizia Jean-Claude Passeron, um homem da segunda função; um guerreiro é um homem que pode abster-se da verdade, que não conhece mais que preconceitos, os seus e aqueles de seu adversário, e que tem a energia suficiente para abater-se sem necessidade de dar uma razão para justificar-se (Veyne, 1985, p. 933).

Tal visão guerreira da amizade estende-se a uma filosofia combatente, já que, afirma Veyne, nesse mesmo artigo, "uma filosofia não tem mais que um uso possível: fazer a guerra; mas não a guerra anterior: a guerra atual. E, por isso, ela deve começar por demonstrar genealogicamente que não existe outra verdade da história, além deste combate"(1985, p. 941).

Eis o caráter da amizade foucaultiana do conceito. O pastor do ser deixa a relativa passividade da escuta, o deslumbramento e a ofuscação que o acometiam na luminosidade da clareira. Ele acorda para um mundo de forças que não se dispõe mais num horizonte, pelo contrário, a indeterminação do mundo o envolve e o atravessa por todos os lados. Toda amizade, inclusive a que se estabelece entre os filósofos, é uma "técnica de si”, para utilizarmos um termo foucaultiano apropriado, que se aplica a vários âmbitos cotidianos da vida grega, entre eles, aos jogos políticos da democracia, à magistratura, ao amor e ao domínio do pensamento e do ensino (pedagogia), como mostrou Foucault ao propor a análise do Alcibiades. ${ }^{16}$

Foucault ao tratar da amizade entre homens, refere-se necessariamente ao "tecido afetivo" que se compõe em uma situação real de guerra. Como, para Foucault, os modos de vidas são construídos em campos de força onde a estratégia define as regras do jogo, podemos dizer que um tecido de amizade sempre se tece, quaisquer que sejam as situações, inclusive a da filosofia, pois 
alguém pode perguntar o que faz com que nessas guerras absurdas, grotescas, nesses massacres infernais, as pessoas, apesar de tudo, tenham se sustentado? Sem dúvida, um tecido afetivo. Não quero dizer que era porque eles estavam amando uns aos outros que continuavam combatendo. Mas a honra, a coragem, a dignidade, o sacrifício, sair da trincheira com o companheiro, diante do companheiro, isso implicava uma trama afetiva muito intensa. Isto não quer dizer: “Ah, está aí a homossexualidade!" Detesto este tipo de raciocínio. Mas sem dúvida se tem aí uma das condições, não a única, que permitiu suportar essa vida infernal em que as pessoas, durante semanas, rolassem no barro, entre os cadáveres, a merda, se arrebentassem de fome; e estivessem bêbadas na manhã do ataque. (Foucault, 1981, p. 38-39)

Ora, voltemos à nossa questão inicial, a saber, por que todo pensar inclui uma relação de amizade, de tal modo que pudemos fazer uma ampla visita ao conceito de amigo e a algumas paisagens que este inclui, segundo as filosofias dos pensadores destacados?

São Deleuze e Guattari que nos auxiliam a dar uma resposta geral a essa questão, em que pese a diversidade da relação de amizade segundo o pensador considerado. $\mathrm{O}$ amigo, para sermos mais precisos, é um "traço de personagem conceitual" que tem a ver com "personagens psicossociais" (Deleuze; Guattari, 1991, p. 68). O amigo se auto-apresenta juntamente com um determinado conceito. Quando um filósofo cria um conceito ou quando alguém estuda um pensamento, automaticamente, esse personagem começa a viver. Embora o traço existencial do conceito se relacione com situações vividas, deve ao pathos do conceito sua expressão, posto que,

os traços de personagem conceituais têm um relacionamento com a época e o meio histórico que somente os personagens psicossociais permitem avaliar. Mas, inversamente, os movimentos físicos e mentais dos tipos psicossociais, seus sintomas patológicos, suas atitudes relacionais, seus modos existenciais, seus estatutos jurídicos, tornam-se susceptíveis de uma determinação puramente pensante e pensada que os arranca seja dos estados de coisa históricos de uma sociedade seja do vivido pelos indivíduos, para deles fazer traços de personagens conceituais. (Deleuze; Guattari, 1991, p. 68)

A lição dos autores a esse respeito é a de que, embora se possa falar, propriamente, de uma amizade platônica, já que envolve a relação com a Idéia e, portanto, com a verdade, de uma amizade nietzscheana baseada na desconfiança, de uma amizade heideggeriana baseada na audição na clareira do ser, e de uma amizade foucaultiana em um campo de batalha na verdade, essas qualificações personalistas, que contêm certos traços existenciais, são resultantes do plano dos conceitos. Em todo pensamento, constrói-se uma relação de amizade como "traço relacional" (Deleuze; Guattari, 1991, p. 69) inerente a uma "pedagogia do conceito" (Deleuze; Guattari, 1991, p. 17). 
O próprio Deleuze delineia o caráter da amizade que podemos pactuar hoje, principalmente em se tratando de seu papel para levar o pensamento adiante. Em curtas cartas trocadas entre ele e o escritor Dionys Mascolo, em 1988, realiza-se uma bela reflexão acerca da amizade. ${ }^{17}$ Ambos concordam que a amizade ainda continua sendo a condição de pensar e aprender, mas os amigos não são como os filósofos gregos que se reuniam para conversar em torno de um determinado objeto cujo conceito se quer conquistar. Ser amigo, em nossos dias, não significa estabelecer diálogo, posto que a amizade, como modo de vida, entrou em uma espécie de campo perigoso dentro do qual seus movimentos se tornaram suspeitos. Isso porque a interlocução que podia haver entre amigos está minada por uma insana produção discursiva que penetra e exaure o próprio veio criativo da amizade. Dessa forma, ser amigo e pensar se revestem de um modo aparentemente contraditório pelo qual, fazer valer uma amizade, antes de tudo, é seguir com o amigo por zonas de penumbra e de silêncio, pois, agora, não é necessário, nem recomendável, "que se fale com o amigo, que se partilhe lembranças com ele, mas, ao contrário, é com ele que se passa por provas como amnésia, a afasia, necessárias a todo pensamento" (Deleuze, 2003, p. 307).

\section{Referências}

DELEUZE, Gilles. Foucault. Paris: Minuit, 1986. . Pourparlers. Paris: Minuit, 1990.

Désir et Plaisir. Magazine Littéraire, n. 325, oct. 1994.

. Correspondance avec Dionys Mascolo. In: LAPOUJADE, David (Ed.). Deux regimes de fous: textes et entretiens 1975-1995. Paris: Minuit, 2003.

DELEUZE, Gilles; GUATTARI, Félix. Qu'est-ce que la philosophie? Paris: Minuit, 1991.

FOUCAULT, Michel. De l'amitié comme mode de vie. Gai Pied, n. 25, p. 38-39, abr. 1981. (Tradução de Wanderson Flor do Nascimento disponível em: <www.unb. $\mathrm{br} / \mathrm{fe} / \mathrm{tef} /$ filoesco/foucault/amitie.html $>$.)

História da sexualidade: o uso dos prazeres. Rio de Janeiro: Graal, 1984. v. 2. . História da sexualidade: o cuidado de si. Rio de Janeiro: Graal, 1988. v. 3. . Résumés des cours, 1970-1982. Paris: Julliard, 1989.

HEIDEGGER, Martin. Sobre o problema do ser. São Paulo: Duas Cidades, 1969. . Introdução à metafisicica. Rio de Janeiro/Brasília: Tempo Brasileiro/Ed. UnB, 1978. 
HEIDEGGER, Martin. Carta sobre o Humanismo. Tradução de Ernildo Stein. São Paulo: Abril Cultural, 1979. (Coleção Os Pensadores).

NIETZSCHE, Friedrich. Jenseits von Gut und Bose; Vorspiel einer Philosophie der Zukunft. In: NIETZSCHE, Friedrich. Drei Bänden, Zweiter Band, Herausgegeben von Karl Schlechta. München: Carl Hanser, 1954.

. Gotzen Damerung oder Wie man mit dem Hammer philosophiert. In: NIETZSCHE, Friedrich. Drei Bänden, Zweiter Band, Herausgegeben von Karl Schlechta. München: Carl Hanser, 1954. . Euvres philosophiques. Paris: Gallimard, 1970. v. 11. . Correspondência. Tradução de Felipe González Vicen. Madrid: Aguilar, [s. d.]. . A gaia ciência. Tradução de P. C. Souza. São Paulo: Cia. das Letras, 2002.

PLATON. Le politique ou de la royauté. In: PLATON. Euvres Complètes. Paris: Gallimard, 1964. t. 2.

VEYNE, Paul. Le dernier Foucault et as morale. Critique, Paris, v. XLIL, n. 471-472, 1985. 